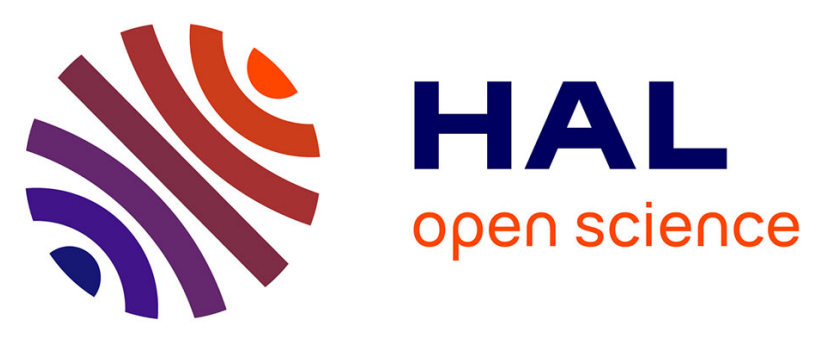

\title{
Exploration and Identification of Cortico-Cerebellar-Brainstem Closed Loop during a Motivational-Motor Task: An fMRI Study
}

Chama Belkhiria, Driss Tarak, Christophe Habas, Hamdi Jaafar, Rémy Guillevin, Giovanni de Marco

\section{To cite this version:}

Chama Belkhiria, Driss Tarak, Christophe Habas, Hamdi Jaafar, Rémy Guillevin, et al.. Exploration and Identification of Cortico-Cerebellar-Brainstem Closed Loop during a Motivational-Motor Task: An fMRI Study. The Cerebellum, 2016, pp.1-14. 10.1007/s12311-016-0801-1 . hal-01467687

\section{HAL Id: hal-01467687 \\ https://hal.parisnanterre.fr/hal-01467687}

Submitted on 10 Oct 2019

HAL is a multi-disciplinary open access archive for the deposit and dissemination of scientific research documents, whether they are published or not. The documents may come from teaching and research institutions in France or abroad, or from public or private research centers.
L'archive ouverte pluridisciplinaire HAL, est destinée au dépôt et à la diffusion de documents scientifiques de niveau recherche, publiés ou non, émanant des établissements d'enseignement et de recherche français ou étrangers, des laboratoires publics ou privés. 


\title{
Exploration and Identification of Cortico-Cerebellar-Brainstem Closed Loop During a Motivational-Motor Task: an fMRI Study
}

\author{
Chama Belkhiria $^{1}$ - Tarak Driss ${ }^{1}$ - Christophe Habas ${ }^{2}$ - Hamdi Jaafar ${ }^{1}$. \\ Remy Guillevin $^{3} \cdot$ Giovanni de Marco ${ }^{1}$
}

\begin{abstract}
The cerebellum is involved not only in motor coordination, training, and memory, but also in cognition and emotion. Lobule VI in particular belongs to sensorimotor, salience, and executive cerebellar networks. This study aims to determine whether lobule VI would constitute an integrative interface between motor and cognitive/emotional circuits during a motor task with verbal encouragement, likely in conjunction with the basal ganglia (reward and motivational system). We used fMRI to identify specific recruitment of cerebellar and striatal systems during physical performance using two motor tasks with and without encouragement. We found that: (i) Force results were higher during verbal encouragement than during basal condition in all participants. (ii) The anterior part of the right lobule VI was activated by motor execution in both tasks, while its posterior part was specifically activated by verbal encouragement. (iii) The closed-connectivity loop maintained motivation induced by verbal encouragement between cerebral and cerebellar through the red nucleus and striatal network. Therefore, right lobule VI is a hubcontrolling sensorimotor and motivates aspects of motor
\end{abstract}

Chama Belkhiria

belkhiriachema@hotmail.fr

1 Laboratoire CeRSM (EA 2931), Equipe “Analyse du Mouvement en Biomécanique, Physiologie et Imagerie”. UFR STAPS, Université Paris Ouest Nanterre La Défense, 200 avenue de la République, 92000 Nanterre, France

2 Service de Neuro-Imagerie, Hôpital des Quinze-Vingts, UPMC Paris 6, 28, rue de Charenton, 75012 Paris, France

3 Assistance Publique-Hôpitaux de Paris, Groupe hospitalier la Pitié Salpêtrière, service de Neuro-Radiologie, Paris, France performance in relation with the red nucleus and the ventral striatum. These results could have important implications for extrapyramidal and multisystem degenerative diseases.

Keywords Lobule VI $\cdot$ Motivation $\cdot \mathrm{fMRI} \cdot$ Motor $\cdot$ Red nucleus $\cdot$ Cerebellum

\section{Introduction}

Verbal encouragement has been shown to improve self-efficacy and physical performance specifically in sports performance, exercise, and rehabilitation [1-3]. Physiological studies, such as incremental tests in competitive runners [4], in non-athletes [5] and in university endurance athletes' performances [6] found better performance following verbal encouragement. Positive verbal encouragement also induced peak force of the elbow flexors during an isometric muscle action [1], $\mathrm{VO}_{2} \max$, blood lactate concentration [7], and Wingate test parameters [8]. Moreover, verbal encouragement facilitates attentional focusing on the motor task and consequently performance improvement [9]. However, to our knowledge, no fMRI studies have yet been carried out to highlight the effect of verbal encouragement on brain activation, especially on networks subserving sensorimotor training/performance, motivation and, likely, attention. Therefore, it can be postulated that at least three cerebral circuits should be recruited: a sensorimotor network including the cerebellum, the ventral striatum for motivation, and the attentional/ executive control network. Moreover, the cerebellum could constitute a hub coordinating these neural circuits.

Firstly, the sensorimotor circuit encompasses: the sensorimotor, medial, and lateral motor cortices, the ventral thalamus, the lenticular nucleus, and contralateral cerebellum (lobules IV-V, VIIIA-B) $[10,11]$. This network is involved in programming, executing, and controlling motor performance by 
modulating the primary motor cortex through cerebellothalamocortical connection [12-14]. During training, performance improvement is associated with shifting activity within the cerebellum and the striatum. One general hypothesis would be that the cerebellum computes error-based signals based on "forward" models and predicts sensory consequence of movement. The cerebellum role in the temporal organization, coordination, and finessing of actions can be conceptualized in terms of adaptive filtering and internal modeling of the body, learned through adaptive processes dependent on sensory prediction errors $[14,15]$. The prominent role of the cerebellum linked to sensorimotor networks and anticipatory control predicts that the cerebellum could play an important part in this force production task, mainly in lobule VI.

Secondly, the cerebellum also participates in the executive control (lobule VII) and the limbic (lobules VI and VIIA-B) networks. Manto et al. [16] postulated that the cerebellar network recruits cerebellar regions (lobule VI/VII) to execute attentional or motivational functions. Clinical and experimental data indicate that direct and indirect links connect the cerebellum to the cortical limbic regions [17, 18]. Animal and human studies show that attentional and motivational impairments occur when posterior lobe lesions affect lobules VI and VII and the limbic system [19, 20]. Therefore, the cerebellum could also take part in reallocating attention to the motor task being accomplished.

Additionally, mobilizing attention in response to encouragement could also be mediated by the ventral striatum implicated in the reward and motivational system. For instance, basal ganglia (mostly the ventral striatum and the pallidum) have been identified as responsible for motivating force production [21, 22]. Work ranging from electrophysiological and lesion experiments in animals to clinical population-based and imaging studies in humans has undoubtedly demonstrated that the basal ganglia, and the striatum in particular, plays a critical role in the planning, learning, and execution of a new motor skill.

Lastly, the cerebellum and basal ganglia are anatomically and functionally interconnected. Results from early imaging studies have revealed gross dynamic functional interactions occurring between the striatum and the cerebellum as subjects are practicing the motor skill until they reach asymptotic performance in the first training session [23].

More recent findings [24, 25] have shown the extent of dynamic cerebral interactions occurring between the striatum, the cerebellum, and the motor cortical areas motor skill learning. The cerebellum projects to the caudate and putamen via the thalamus, while the subthalamic nucleus is connected back to the cerebellum via pontine nuclei. Tractography studies have also found cerebello-striatal interconnections in humans. Therefore, cerebellar and basal ganglia may interact during reward-based or motivational learning.

This study aims to explore the role of the cerebro-cerebellar and striatal network during a motor performance enhanced by verbal encouragement. We used fMRI to detect the results of a specific activation of cognitive, motivational, and motor regions in the presence and absence of verbal encouragement associated with a handgrip task. Based on resting-state connectivity and functional imaging studies, we predicted that: (1) Lobule VI and ventral striatum might be specifically recruited and that (2) Lobule VI might constitute a hub for integrating motor, motivational, and cognitive aspects of motor performance during verbal encouragement.

\section{Materials and Methods}

\section{Participants}

Twenty-two right-handed volunteers (eleven men and eleven women, aged $30.3 \pm 4.3$ years) participated in the study. The participants were students from sport sciences. They were instructed to close their eyes and to motivate themselves. They had to strongly concentrate on their movements and to press the handgrip as hard as possible without making any sudden movements. All subjects were healthy and had no known neuromuscular disorders at the time of the study. They also answered a questionnaire, which ensures the security of the examination. Written informed consent was obtained from all participants. The study was approved by the local ethics committee.

\section{Paradigm}

The protocol began with a familiarization and warm-up phase with the handgrip device. Lying under the MRI scanner, participants were asked to squeeze the handgrip device as hard and as fast as possible with headphones placed on their ears following two tasks: (i) a verbal encouragement task: participants were verbally encouraged throughout the contraction. A recorded human voice repeated firmly "GO" 20 times during $4.4 \mathrm{~s}$ to encourage the subjects. The vocal encouragement was recorded by WavePad Audio Editing Software. Verbal encouragements accompanied the movement to enhance the motivation so that participants could perform better force contraction (ii) a non encouragement task: exactly the same task as the first one but without verbal encouragement (Fig. 1). The order of the tasks was counterbalanced over subjects.

Every condition of the task included five trials. Each one began with a preparation period $(6.6 \mathrm{~s})$ where subjects were asked to motivate themselves and to concentrate on the movement that they had to execute. Then, the contraction period (4.4 s) started when participants heard the starting signal "GO". They had to perform the task of squeezing the handgrip as hard as possible, developing a maximal voluntary contraction and then stop after a period of $4.4 \mathrm{~s}$ of muscular 
Fig. 1 Scheme of paradigm. Participants executed five maximal voluntary contractions in each condition using handgrip device. In verbal encouragement condition, execution period was associated to pre-registered verbal encouragements

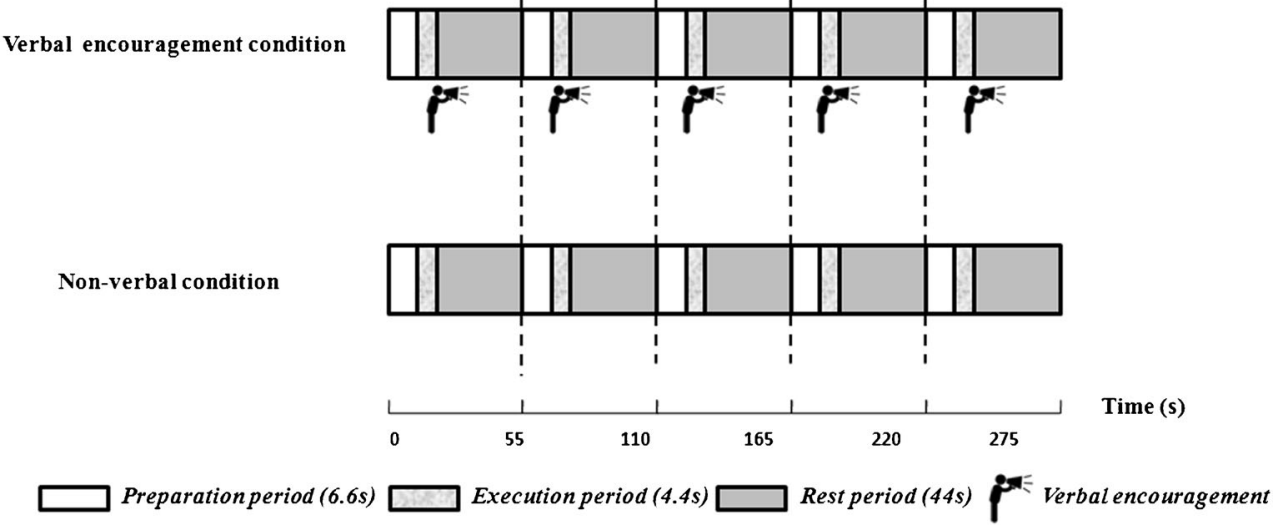

contraction. Finally, a long rest period (44 s) allowed participants to recover effort (resting state).

\section{Force Data Acquisition}

Force data was displayed on the laptop computer monitor in the control room. The MRI machine (General Electric) and Biopac system (Biopac MP150, System Inc., Santa Barbara, CA) simultaneously recorded the functional brain images and force data. Handgrip force was measured by a pressure transducer (TSD121B-MRI Hand Dynamometer). The handgrip device was an 8-m long cable, weighed $323 \mathrm{~g}$ and was connected to Biopac MP150. The metal-free handgrip device was held in the subject's right hand in the MRI room and was connected to the Biopac located in the MRI control room. The output of the transducer was connected to an amplifier, DA100C, whose output was directed to AcqKnowledge software (Version 4.2, System Inc., Santa Barbara, CA). This amplifier simultaneously recorded on the hard disk of a laptop computer. The force signal was digitized at 200 samples/s. Moreover, the force output was amplified through a pressure gauge amplifier, and the data were sampled at $200 \mathrm{~Hz}$.

\section{fMRI Data Acquisition}

Neuroimaging data were acquired with a 3-T, whole-body MRI system, equipped with a head volume coil (Signa; General Electric Medical System, Milwaukee, WI). Functional images with blood-oxygen-level-dependent (BOLD) contrast enhancement were acquired for each participant. Single-shot echo-planar images (EPIs) were also acquired using a typical T2* weighted gradient-echo sequence. Two runs of 124 EPI volumes with no gap were acquired for each subject $(\mathrm{TR} / \mathrm{TE}=2215 / 30 \mathrm{~ms}$; flip angle $=80$; matrix $=64 \times 64 ; \mathrm{FOV}=240 \times 240 \mathrm{~mm}^{2} ;$ isotropic voxel volume $=52.7 \mathrm{~mm}^{3}$ ). At the end of the first functional run, a series of T1-weighted 3D anatomical images was collected in order to provide detailed anatomical information.
Conventional 3D imaging used an SPGR sequence (matrix: $256 \times 256$; flip angle: 15 ; TR/TE: 6.608/2.828 ms; 124 slices, $1.2 \mathrm{~mm}$ thickness). Head movements were restrained by cushions in order to reduce motion-related artifacts. All MR data were acquired in a single session for each subject.

\section{fMRI Image Pre-processing}

Image processing was performed using Statistical Parametric Mapping (SPM12 software from the Methodology Group, Wellcome Department of Imaging Neuroscience, Institute of Neurology, London, UK: http://www.fil.ion.ucl.ac.uk/spm). SPM run with software Matlab R2012a.

For each participant, four scans were discarded; all EPI volumes were corrected to adjust for within-volume time differences and then realigned with the last volume to correct for head movements. Spatial smoothing was performed with an $8 \mathrm{~mm}$ t Gaussian kernel. Hemodynamic responses were modeled as a box-car function, convolved with a synthetic hemodynamic response function. To minimize the contamination of the data with movement artifacts, the motion vectors derived from the realignment were used as regressors to model the data.

\section{Group Statistical Parametric Mapping}

A single-subject fixed-effect model was created for each individual participant, in order to perform the based-conditions random-effect analysis. In each single-subject analysis, a significance level of $P=0.005$ uncorrected was used to detect activated voxels. While data were acquired for the brain as a whole, SPM was constrained to specific hypotheses concerning cerebral, cerebellar, and brainstem regions. As we had a prior hypothesis about the localization of change, significance levels for $t$ statistics were set at $P<0.005$ uncorrected. In addition, we performed a small volume correction 
(SVC) at the voxel level using an $8 \mathrm{~mm}$ of radius around the voxel with the higher level of significance into the clusters that passed uncorrected thresholding, corrected for multiple comparisons, using $p$ family-wise error $(\mathrm{FEW})<0.05$. The small volume correction avoided false positive results by reducing the number of voxels entering the statistical computation.

Local maxima were located within anatomical regions and then assigned to a MNI coordinate and a Brodmann area.

\section{Regions of Interest}

Considering that our task solicits four functions: Language comprehension, motivation, concentration, and motor involvement, we looked for the main cortical areas responsible of these functions in the literature. (i) Left Primary Motor Cortex (M1) [BA 4], Kuypers [26] defined the motor cortex as the region giving origin to the corticospinal (pyramidal) tract. It corresponds to the agranular cortex of Brodmann's areas 4 located in the precentral gyrus and corresponds to the primary motor cortex, characterized by the presence of the giant pyramidal cells of Betz. (ii) Right "Orbitofrontal Cortex" (OFC) [BA 47] is a brain area implicated in the motivation and the experienced value of rewards [27-33]. This brain region is known to provide a common currency function, ensuring the value of different types of rewards to be represented and analyzed on a common value scale [34-37]. (iii) Right "Dorsolateral Prefrontal Cortex" (DLPFC) [BA 46] is known for its involvement in the executive functions. It is an umbrella term for the management of cognitive processes, including working memory, cognitive flexibility, planning, and attentive concentration [38, 39]. DLPFC is also involved in information monitoring and abstract rule processing [40-44]. (iv) Left "Superior Temporal Gyrus" (STG) [BA 22] encompasses Wernicke's area. It supports the recognition of patterns in spoken language, language comprehension, semantic processing, and language interpretation [45]. For the ROI construction, we used WFU Pickatlas toolbox which automatically generates segmented ROI templates in Montreal Neurological Institute (MNI) space [46]. The ROIs defined in this atlas were originally based on manual delineation of the brain region borders according to the MNI coordinates.

\section{Psychophysiological Interactions}

In order to highlight connectivity between the involved regions, a psychophysiological interaction (PPI) analysis was performed at three levels; cerebral, cerebellar, and brainstem. A psychophysiological interaction (PPI) analysis was conducted to investigate interactions among brain regions [47]. A PPI analysis tests the hypothesis that activity in one brain area can be explained by an interaction between the presence of a cognitive process and activity in another region of the brain. We predicted that activity of the source region will covary with activity of the target region. In our study, the PPI analysis was performed to examine the enhancement of effective connectivity between a source region and other brain regions during verbal encouragement $[47,48]$. The connectivity is considered to be proportional to synaptic strength and to the number of synapses a target neuron establishes within the source population. The latter additionally depends on the activity of the target neurons.

\section{PPI from Cerebrum Regions to the Cerebellum}

Firstly, we tested 4 different PPI from cortical brain regions to the cerebellum. At the cortical level, we independently selected right OFC, right DLPFC, left STG, and left M1 as sources areas.

These regions are known to exert motivational, cognitive, and motor functions at the cortical level and to project to the cerebellum. Several target areas in the cerebellum have been identified, as it is known that the cerebellum is involved both in cognitive and motor processes. Thereby, we used a maximum probability map (MPM) in order to locate precisely which cerebellum areas were the most activated in the verbal vs. non-verbal condition. A MPM is a summary map of different histological maps. It is based on the idea of attributing each voxel of the reference space to the most likely cytoarchitectonic area, or the most likely myeloarchitectonically defined fiber-tract at this position. MPMs allow the definition of non-overlapping representations of all areas from a set of inevitably overlapping probabilistic maps [46, 49]. We used MPM Anatomy Toolbox v1.5 [46, 49, 50] to predict the cluster size and the percentage of activation in right anterior and posterior parts and in neighboring regions of lobule VI.

\section{PPI from the Cerebellum to the Red Nucleus and Ventral Striatum}

Based on the results of MPM, we independently selected right posterior and anterior parts of lobule VI as our source. The target area was first the left red nucleus. We then tested PPI connectivity from the right anterior and posterior lobule VI to the ventral stiratum. Moreover, we selected the red nucleus and the ventral striatum as target areas to explore the possibility that these structures may be implicated in cognitive and motivational functions.

\section{PPI from the Red Nucleus to Cortical Regions}

Finally, we tested four red nucleus PPI (source area) to right OFC, right DLPFC, left STG, and left M1 (target areas). On the cerebellar and brainstem levels, the assumption was that the red nucleus could reinforce and modulate cognitive, motivational, and motor processes. 


\section{Results}

\section{Force Results}

A paired $t$ test was conducted on mean force over time $(\mathrm{N})$, which represents the total force divided by the force duration (4.4 s). While subject to verbal encouragement, participants squeezed the handgrip with greater force than in a non-verbal setting. Mean force for five trials measured in the whole group in the verbal condition (mean: 29.26, SD: 11.43) was significantly higher relative to the non-verbal condition (mean: 26.97, SD: 12.12) $(t=3.29, P=0.004)$.

\section{fMRI Results}

\section{SPM Analysis}

Table 1 presents the statistical parametric results for the whole brain concerning the contrast "verbal encouragement versus no verbal encouragement." Table 1 is partitioned in the cerebellum, brainstem, and cerebrum areas, and shows $t$ values with a threshold at an uncorrected $p<0.005$ value. The resulting SPM maps revealed significant activations in right and left lobule VI, in right DLPFC, in right, and left OFC, in right, and left M1, in left STG, and in the left red nucleus.

\section{PPI and MPM Analyses}

Table 2 a shows the connectivity from cerebral source regions to cerebellar target areas. Consistent with the literature and our hypothesis, the left M1 is significantly (FWE-corrected $P=0.001)$ connected to the right anterior lobule VI area (Fig. 2a). The right OFC, right DLPFC, and left STG are significantly connected (FWE-corrected $P<0.003$ ) with the right posterior lobule VI area (Fig. 2b). The extent of the activity in Fig. $2 \mathrm{~b}$ takes into account the activity which overlaps for the three regions.

Table 3, reporting detailed activity in target areas, displays cytoarchitectonic area/target area ratio (percentage), cluster size (voxels number), and MNI coordinates $(\mathrm{X}, \mathrm{Y}, \mathrm{Z})$ that correspond to SUIT probabilistic atlas of the cerebellar lobules in the anatomical space defined by the MNI152 template [51] as well as MRI atlas of the human cerebellum [52]. MPM analysis reveals that the source region M1 (Fig. 2a, Table 3) co-activates with a cluster located on the right anterior lobule VI (132 voxels) and a cluster located on the right lobule V (51 voxels).

Source areas OFC, DLPFC, and STG (Fig. 2b, Table 3) present two common co-activation clusters: one in posterior lobule VI of the right cerebellum hemisphere, the second one in the right lobule VII (Crus I). The MPM analysis reveals that these cognitive and motivational areas were more associated with the right posterior lobule VI than with the right posterior lobule VII (Crus I). For example, considering the source region OFC, the cluster in the posterior lobule VI (67 voxels) target area was considerably larger than that of the right lobule VII (Crus I) (6 voxels).

Table $2 \mathrm{~b}$ shows the connectivity from anterior and posterior right lobule VI source areas to brainstem target area. In line with the literature and our hypothesis, the PPI analysis reveals that anterior and posterior lobule VI source areas (Fig. 2) are significantly connected (FWE-corrected $P<0.05$ ) to the red nucleus (MNI coordinates: $-9-22-4$ and $-3-22-5$ respectively) (Fig. 3a).

The activity appears to be mostly localized in the caudal ventrolateral level of the red nucleus. This region corresponds to the magnocellular red nucleus, which gives rise to the crossed rubrospinal tract to spinal motor neurons and interneurons of distal muscles.

Table $2 \mathrm{c}$ shows the connectivity from anterior and posterior right lobule VI source areas to the ventral striatum target area. The PPI analysis reveals that anterior and posterior lobule VI source areas (Fig. 3b) are significantly connected (FWEcorrected $P<0.05)$ to ventral striatum.

Table $2 \mathrm{~d}$ shows the connectivity between the left red nucleus to left M1, right OFC, right DLPFC, left STG. We selected the left red nucleus because of its decussation with the lobule VI; we did not find any activity in the right red nucleus. The left red nucleus source area is functionally connected (FWE-corrected $P<0.05$ ) to left M1 (110 voxels), right OFC (177 voxels), right DLPFC (98 voxels), and left SFG (95 voxels) (Fig. 3c).

Figure 4 illustrates the changes of regression slope (PPI) between the left red nucleus activity $(-3,-22,-11)$ and right OFC activity $(48,17,-5)$, depending on verbal encouragements.

This graphic highlights the most important interaction found in Table $2 \mathrm{~d}(t=4.45 ; P=0.01)$, which took place between the red nucleus (brainstem) and the OFC (cerebrum). This result supports our hypothesis that the motivational component of the task is possibly maintained through this interaction.

Taken together, the results indicate significant connectivity from left M1 to the right anterior lobule VI of the cerebellum $(P=0.001)$ as well as significant connectivity from right $\mathrm{OFC}$ $(P=0.003)$, right DLPFC $(P=0.02)$, and left SFG $(P=0.001)$ to the right posterior lobule VI of the cerebellum. There is also significant connectivity $(P=0.03)$ between both the right anterior and posterior lobule VI of the cerebellum to the left red nucleus (magnocellular part). Connectivity from left red nucleus also shows significant values to left M1 (0.03), to right OFC (0.03), to right DLPFC (0.02), and to left STG (0.03) (Fig. 5).

These observations suggest that connectivity could form closed-loop connections. Cortical motor area (left M1), cortical motivational, and cognitive areas (right OFC, right DLPFC, and left SFG) project respectively to right anterior and posterior lobule VI areas. In turn, these areas project to the 
Table 1 Results of activated regions in verbal versus no verbal encouragement contrast

\begin{tabular}{|c|c|c|c|c|c|c|c|c|c|}
\hline \multirow[t]{3}{*}{ Regions } & \multirow[t]{3}{*}{ BA } & \multicolumn{3}{|c|}{ Left side } & \multirow[t]{3}{*}{$t$} & \multicolumn{3}{|c|}{ Right side } & \multirow[t]{3}{*}{$T$} \\
\hline & & \multicolumn{3}{|c|}{ Stereotaxic coordinates } & & \multicolumn{3}{|c|}{ Stereotaxic coordinates } & \\
\hline & & $X$ & $Y$ & $Z$ & & $X$ & $Y$ & $Z$ & \\
\hline \multicolumn{10}{|l|}{ Cerebellum } \\
\hline Lobule VI (Declive) & & 0 & -55 & -11 & $2.72 *$ & 9 & -73 & -14 & $3.84 *$ \\
\hline Lobule V (Culmen) & & -15 & -31 & -14 & $2.56^{*}$ & 24 & -37 & -26 & $2.98^{*}$ \\
\hline Crus I/II (Tuber) & & -42 & -58 & -29 & 2.08 & 39 & -67 & -23 & $2.94 *$ \\
\hline \multicolumn{10}{|l|}{ Brainstem } \\
\hline Red nucleus & & -3 & -22 & -11 & $2.87 *$ & - & - & - & - \\
\hline \multicolumn{10}{|l|}{ Cerebrum } \\
\hline DLPFC & 46 & - & - & - & - & 45 & 29 & 10 & $3.24 *$ \\
\hline Superior temporal gyrus & 22 & -48 & -43 & 10 & $2.54 *$ & & & & \\
\hline Motor cortex & 4 & -39 & -19 & 55 & $3.37 *$ & 48 & -16 & 40 & 1.98 \\
\hline Supplementary motor area & 6 & -12 & 23 & 49 & $3.02 *$ & 15 & -25 & 49 & $2.72 *$ \\
\hline Orbitofrontal cortex & 47 & -45 & 14 & -5 & $2.73 *$ & 48 & 17 & -5 & $2.94 *$ \\
\hline Striatum ventral & & -15 & -1 & 4 & $2.64 *$ & 21 & -4 & 1 & $2.39^{*}$ \\
\hline Putamen & & -27 & -1 & 13 & $2.36^{*}$ & 27 & 11 & 1 & 3.22 \\
\hline Thalamus & & -9 & -4 & 4 & $5.97^{*}$ & 9 & -16 & 7 & $2.85^{*}$ \\
\hline Insula & 13 & -45 & -19 & 10 & $3.37^{*}$ & 39 & 8 & 13 & $3.02 *$ \\
\hline
\end{tabular}

$B A$ Brodmann areas; $X, Y, Z$ : MNI coordinates, $t$ values, and FWE-corrected $p$ values for multiple comparisons $(* P<0.05)$

left red nucleus, from which the same cortical areas (left M1, right $\mathrm{OFC}$, right DLPFC, and left SFG) receive input.

Figure 5 shows the significant connectivity that we examined between cerebral, cerebellar, and brainstem regions reinforced by the verbal encouragements. The numbers reflect FWE-corrected $p$ values for each of the connected regions.

\section{Discussion}

The present study investigated whether verbal encouragement during a unilateral handgrip task might induce changes in force production, brain activity, and connectivity between the cerebrum, the cerebellar, and the brainstem in healthy

Table 2 Connectivity from source to target regions

\begin{tabular}{|c|c|c|c|c|c|}
\hline PPI connectivity direction (from-to) & Source regions $(x y z)$ & Target regions $(x y z)$ & Cluster size & $t$ & $P_{\mathrm{FWE}}$ \\
\hline \multirow[t]{6}{*}{ (a) Cerebral-cerebellar regions } & & & \multicolumn{3}{|c|}{ Anterior lobule VI } \\
\hline & L M1 (-39-19 55) & R lobule VI (36-46-26) & 616 & 6.98 & 0.001 \\
\hline & & Posterior lobule VI & & & \\
\hline & R OFC (48 17-5) & R lobule VI (24-70-23) & 461 & 4.54 & 0.003 \\
\hline & R DLPFC (45 29 10) & R lobule VI $(9-82-17)$ & 617 & 7.75 & 0.001 \\
\hline & L STG $(-48-4310)$ & R lobule VI (24 -73-20) & 567 & 6.57 & 0.001 \\
\hline \multirow[t]{2}{*}{ (b) Cerebellar regions-red nucleus } & R Anterior lobule VI (24-74-21) & L Red nucleus $(-9-22-4)$ & 232 & 2.41 & 0.03 \\
\hline & R Posterior lobule VI (36-46-26) & L Red nucleus ( $-3-22-5)$ & 254 & 2.69 & 0.03 \\
\hline \multirow[t]{2}{*}{ (c) Cerebellar regions-ventral striatum } & R Anterior lobule VI (24-74-21) & L Ventral striatum $(-183-4)$ & 220 & 2.29 & 0.03 \\
\hline & R Posterior lobule VI (36-46-26) & L Ventral striatum $(-135-6)$ & 240 & 2.45 & 0.03 \\
\hline \multirow[t]{4}{*}{ (d) Red nucleus-cerebral regions } & L Red nucleus $(-3-22-5)$ & L M1 (-51 -7 43) & 110 & 2.66 & 0.03 \\
\hline & & R OFC (33 32-2) & 177 & 4.45 & 0.01 \\
\hline & & R DLPFC (45 41 16) & 98 & 3.24 & 0.02 \\
\hline & & L STG $(-48-22-2)$ & 95 & 2.49 & 0.03 \\
\hline
\end{tabular}

. Psychophysiological analyses $(P P I)$ at a thresholded with an uncorrected $P<0.05$. Listed are peaks significant at $P<0.05$ FEW corrected. $\mathrm{x}, \mathrm{y}$, $\mathrm{z}=$ Montreal Neurological Institute $(M N I)$ coordinates of the peak values; cluster size $=$ number of voxels at $P<0.05$ uncorrected; $t \mathrm{t}$ value of the peak, $L$ left, $R$ right 


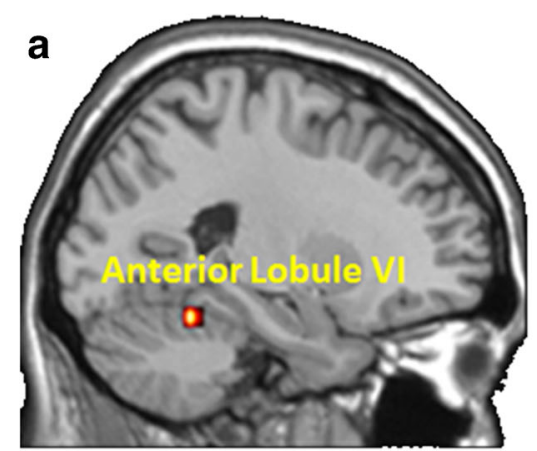

Fig. 2 Activity patterns of anterior and posterior lobule VI displayed on the MNI single-subject template. a Cluster revealed by the PPI from left motor cortex source region. b Cluster revealed by the PPI from right

individuals. Overall, the current results support the hypothesis that the right lobule VI of the cerebellum could constitute a hub that integrates motor, cognitive, and motivational functions. Lobule VI integrates these functions and sends them back polysynaptically to said cortex through the left red nucleus.

\section{Force}

All subjects had a significantly higher mean force in verbal conditions than in non-verbal conditions. These muscular results are in line with other studies performed in physiology: (1) verbal encouragement improved performance in different fields such as: (2) Wingate test aerobic parameters [8], (3) $\mathrm{VO}_{2}$ max and blood lactate concentration during a treadmill test [7], (4) muscular endurance [53], (5) elbow flexors during an isometric muscle action [1], (6) knee extension [3], and (7) triceps surae flexion [54] during maximal voluntary isometric contraction. Belanger and McComas [55] claimed that the activation of motor units may be inhibited when a maximal

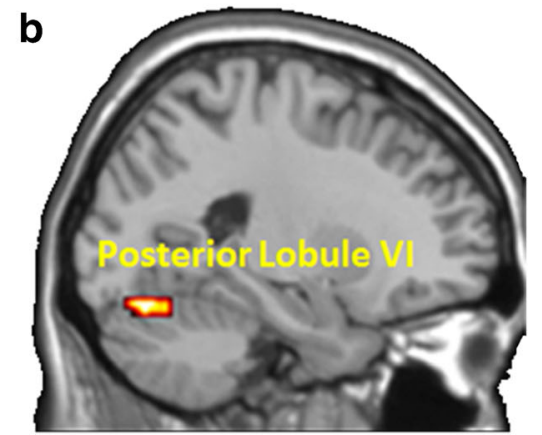

DLPFC. The extent of the activity in figure a takes into account the activity which overlaps for the three source regions (OFC, DLPFC, and STG)

voluntary contraction is required due to a supraspinal drive acting on the motor units. McNair et al. [1] assessed that verbal encouragement may lead to a disengagement of this supraspinal inhibition, thus resulting in an enhancement of muscle strength.

\section{Lobule VI Forms a Hub}

PPI analysis revealed that the left M1 is significantly connected to the right anterior lobule VI area (Fig. 2a). MPM analysis revealed that the source region M1 (Table 3) co-activates with a cluster located on the right anterior lobule VI and with a cluster located in the right lobule $\mathrm{V}$. The majority of the activated voxels $(38 \%)$ were assigned to lobule VI, whereas a smaller part of the cluster (14.9\%) was allocated to the lobule $\mathrm{V}$ adjacent to lobule VI.

The present findings corroborate with human and nonhuman studies showing that motor-related cortices project primarily to the contralateral anterior cerebellar lobe (lobules IV) with an extension into medial lobule VI, and lobule VIII
Table 3 Functional activation clusters in target areas

\begin{tabular}{|c|c|c|c|c|c|c|}
\hline \multirow[t]{2}{*}{ Source area } & \multirow[t]{2}{*}{ Target areas } & \multirow{2}{*}{$\begin{array}{l}\text { Cytoarchitectonic } \\
\text { area target area }(\%)\end{array}$} & \multirow{2}{*}{$\begin{array}{l}\text { cluster size } \\
\text { [voxel] }\end{array}$} & \multicolumn{3}{|c|}{ Anatomical MNI } \\
\hline & & & & $X$ & $Y$ & $Z$ \\
\hline \multicolumn{7}{|l|}{ Motor area } \\
\hline \multirow[t]{2}{*}{ L Motor cortex } & R Anterior lobule VI & $38,5 \%$ & 132 & 36 & -46 & -26 \\
\hline & R Lobule V & $14,9 \%$ & 51 & 12 & -55 & -23 \\
\hline \multicolumn{7}{|c|}{ Motivational and cognitive areas } \\
\hline \multirow[t]{2}{*}{ R OFC } & R Posterior lobule VI & $65.6 \%$ & 67 & 24 & -70 & -23 \\
\hline & R Lobule VIIA (Crus I) & $6.6 \%$ & 6 & 36 & -52 & -32 \\
\hline \multirow[t]{2}{*}{ R DLPFC } & R Posterior lobule VI & $64.9 \%$ & 337 & 9 & -82 & -17 \\
\hline & R Lobule VIIA (Crus I) & $7 \%$ & 36 & 21 & -85 & -20 \\
\hline \multirow[t]{2}{*}{ L STG } & R Posterior lobule VI & $56.2 \%$ & 159 & 24 & -73 & -20 \\
\hline & R Lobule VIIA (Crus I) & $20.3 \%$ & 7 & 18 & -91 & -15 \\
\hline
\end{tabular}

Cluster maxima assigned to the most probable cytoarchitectonic area when present in the SPM Anatomy Toolbox [49]. Listed are cytoarchitectonic area; cluster size; stereotaxic coordinates (specified in anatomical MNI space) of clusters revealed by the PPI analyses; $L$ left and $R$ right 


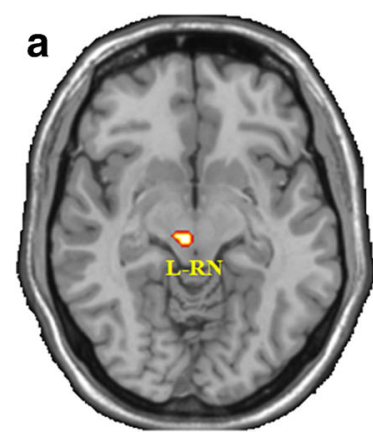

Figure 3 Activity patterns of target areas displayed on the MNI singlesubject template. a Clusters revealed by the PPI from the right posterior lobule VI source region to the left red nucleus. b Clusters revealed by the
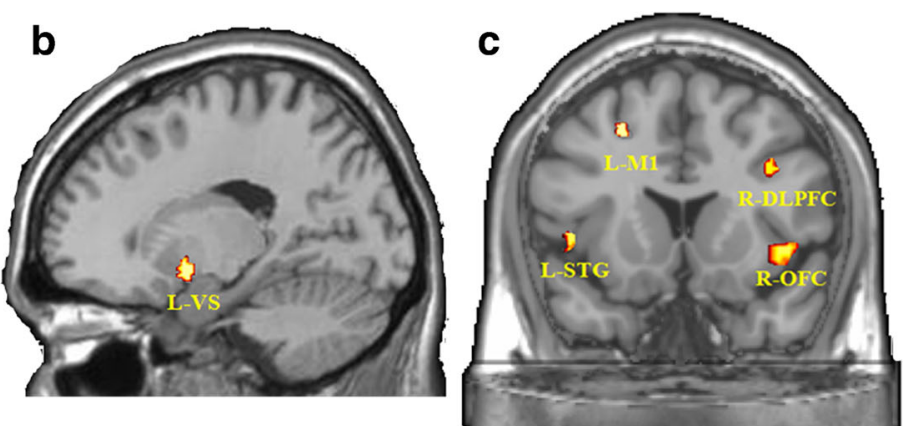

PPI from the right posterior lobule VI source region to left ventral striatum. c Clusters revealed by the PPI from the left red nucleus to left $\mathrm{STG}$, left M1, right DLPFC, and right OFC. $L$ left; $R$ right

posterior lobule VI than with the right posterior lobule VII. The majority of the activated voxels $(>60 \%)$ were within lobule VI, whereas a smaller part of the cluster $(<10 \%)$ was situated in the adjacent area of lobule VI (lobule VII, Crus I) (Fig. 2b).

This anatomical segregation is in agreement with O'Reilly and colleagues [82] who divided the cerebellum into at least two functional zones: the primary sensorimotor (Lobules V, VI, and VIII) and supramodal (lobules VIIA, Crus I, and II). Likewise, Stoodley and colleagues [83] found that cognitive tasks tend to engage lateral regions of lobule VI and lobule VII (Crus I, Crus II, and VIIB). These observations confirmed our hypothesis, which stipulated that lobule VI might constitute a hub for integrating cognitive aspects of motor performance during verbal encouragement.

To facilitate the generation of future hypotheses related to motor timing or supplementary closed-connectivity loops, data for activation within SMA are also reported in Table 1. The SMA has been shown to play a special role for the coordination and initiation of temporal organization of sequencing

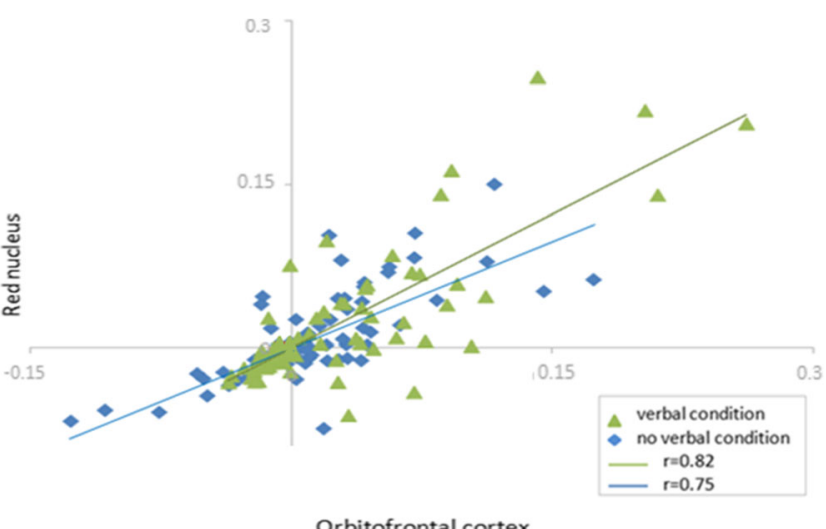

Fig. 4 Graphical display illustrating the psychophysiological interaction between the left red nucleus and right OFC for all subjects. The $B O L D$ values for the voxels $(-3,-22,-11)$ in the left red nucleus and $(48,17,-5)$ in the right $\mathrm{OFC}$ are plotted during verbal (green) non-verbal (blue) conditions. Slopes are significantly different between the two conditions $(P<0.05)$. There is no significant difference between the correlation coefficients 


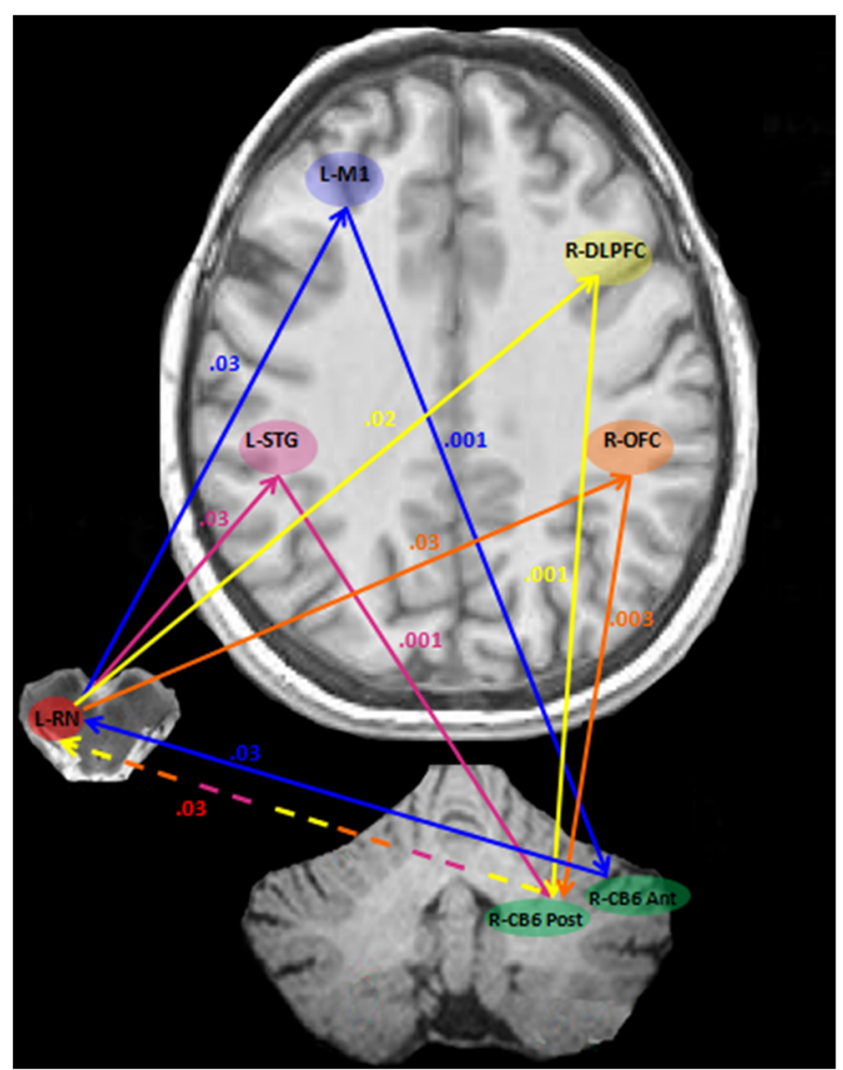

Fig. 5 Functional connectivity from all interactions between the cerebrum, the cerebellum, and the red nucleus. The arrows reflect connectivity from the source to the target area, each of these with a varying starting path, all of them ending in the left red nucleus. The blue arrow shows PPI from L-M1 to the cerebellum (R anterior Lobule $\mathrm{VI}$ ), while the yellow ones illustrate PPI from R DLPFC to the cerebellum ( $\mathrm{R}$ posterior Lobule VI). The orange arrows show PPI from R OFC to the cerebellum (R posterior Lobule VI), and the purple arrows show PPI from L STG to the cerebellum (R posterior Lobule VI). The numbers reflect FWE-corrected $p$ values (all $P<0.05$ ). $C B 6$ ant Anterior Lobule VI, CB6 post Posterior Lobule VI, $L$ left, $R$ right

movements, in particular during self-initiated and multisegmental voluntary movements [84-86]. Also, SMA has been shown to be the recipient of posterior parietal axons both directly and via the basal ganglia. SMA and lateral premotor cortex widely projects to basal ganglia system which is thought to play a key role in selecting and adapting motor programs based on initial conditions using proprioceptive input, or in formulating an internal model of body kinesthesia. Moreover, recent findings propose an SMA involvement in both classical and "extended" mirror neuron regions during the observation and execution of movements $[87,88]$.

\section{Red Nucleus}

PPI analyses reveal that the red nucleus is concurrently connected to both the right lobule VI (anterior and posterior parts) and cortical areas (left STG, left M1, right OFC, and right DLPFC).
Firstly, PPI analysis reveals that right anterior and posterior parts of the lobule VI source area are significantly connected to the left red nucleus (Table 2b, Fig. 3a). This result indicates that the red nucleus integrates motor and motivational functions established from anatomical connection with the right lobule VI. This finding is supported by a functional connectivity MRI study [89] using independent component analysis, which identifies that the anterior motor cerebellum (lobules $\mathrm{V}-\mathrm{VI}$ ) and the posterior cerebellum (lobules VI-VII) are intrinsically connected networks encompassing RN. Secondly, PPI analysis reveals also that RN is connected with left STG, left M1, right OFC, and right DLPFC (Table 2d, Fig. 3c) reporting a key motor, cognitive, and motivational involvement of the red nucleus. More specifically, the positive correlation between OFC and RN exposed an important interconnection between both structures (Fig. 4). This result suggests that $\mathrm{OFC}$ activity is modulated by $\mathrm{RN}$ and that the motivational component of the task is possibly maintained through this interaction. Nioche and colleagues resting-state study [89] have shown that the human $\mathrm{RN}$ participates in a widespread cortical functional network including associative prefrontal, parietal, occipital, and temporal areas. The present interaction between OFC and RN has already been confirmed by anatomical connections between $\mathrm{RN}$ and cortical cortex demonstrated in Nioche study [89]. They highlighted that RN displayed bilateral temporal coherences with the prefrontal cortex (BA 11/45/47), (BA7), the superior temporal cortex (BA 20), DLPFC (BA 9), and the thalamus.

Taken together, PPI results from the cortical cortex (left STG, Left M1, Right DLPFC, and right OFC) to the right anterior and posterior lobule VI, to the left red nucleus and back to the cortical cortex (Table 2) suggest the existence of a closed-connectivity-loop modulated by the red nucleus. This submission is broadly consistent with the neuroanatomical studies that have shown bidirectional pathways between the cerebellum areas involved in motor and cognitive domains and their counterparts in the cerebral cortex. The motor and non-motor cerebellum regions form bidirectional connections with the motor, prefrontal, posterior parietal, and superior temporal cortices, limbic system, brainstem nuclei via corticopontocerebellar pathways [18, 90, 91]. The cerebellar motor domains have been shown to both receive inputs from and send outputs to M1, forming a closed-loop circuit.

Regions within the non-motor domains of the cerebellar cortex also participate in distinct closed-loop circuits with regions of the prefrontal cortex [56, 92]. Using DTI-based tractography in human, Palesi and colleagues [93] showed contralateral massive efferences from neocerebellum to prefrontal cortex (BA 9-12, 25, 46-47), parietal (BA 1-3), and temporal cortices (BA 41-42), and, to a lesser extent, to basal ganglia.

Thus, multiple closed-loop circuits represent a fundamental feature of interactions between the cerebellum and the cerebral cortex. The cerebellum displays a multi-scale modular 
organization including for instance biochemical longitudinal zonation with zebrin [94-98], olivocerebellar microzones grouped into functional microcomplexes consisting of multiple cerebello-olivo-cerebellar modules [98-103] and that, lastly, are segregated into parallel, large-scale closed loops subserving specific sensorimotor, cognitive, and emotional functions [100, 104-106]. These anatomical bases could explain that cerebellum modular organization may stand an important role for treating cognitive, motivational, and motor output induced by the task through the cerebro-cerebellar anatomical connections.

The polysynaptic interactions associated with the cognitive role of the RN related to salience detection and executive control [89] lead to the modulation of motivation through a closed-connectivity loop. Essentially, the cerebellar links with the OFC, DLPFC, and STG are in line with the cerebellar theory of Ito [107]. The present connectivity patterns also provide support for a distinct motivational/default network in the cerebellum [108, 109].

Otherwise, cognitive and motor functions could also be modulated via another loop, the neocerebello-rubro-olivoneocerebellar loop. The main efferent from the human red nucleus is that to the bulbar principal olivary nucleus (PO) and DTI studies $[110,111]$ have shown that RN is strongly connected to PO via the central tegmental tract. The PO neurons' axons, the climbing fibers, terminate as excitatory inputs onto Purkinje cells in the cerebellar cortex. The Purkinje cells, consecutively, exert a powerful synaptic inhibition onto these cerebellar nuclear neurons [112]. Neuronal output from dentate nucleus reaches the thalamus through the (parvicellular part of the) red nucleus but without forming synapse with rubral neurons [113].

The neocerebello-rubro-olivo-neocerebellar loop is implicated in motor and mainly cognitive networks and functions [114]. The cortical projections are directed to the red nucleus, which sends efferents in the central tegmental tract to olivary subnuclei. These subnuclei receive spinal cord input and which are reciprocally interconnected with the cerebellar motor and non-motor lobules.

Considering the major role of the olivocerebellar system in motor learning, this loop might have played an important role in this study. However, we could not confirm this connectivity loop, probably because of anatomical and statistical reasons: (1) the small size of the PO. The PO is a small nucleus compared to the spatial resolution of smoothed functional images. (2) Restriction may be due to the low spatial resolution of the AMRI images and statistical thresholding may have been too stringent.

\section{OFC and Ventral Striatum}

Activation of right $\mathrm{OFC}$, right and left ventral striatum (Table 1) is correlated with verbal encouragement. In humans, motivational deficits can arise from damage to the basal ganglia, diencephalon, limbic system, nucleus accumbens, nucleus of the diagonal band of Broca, internal capsule, globus pallidus, and/or precommissural gray and OFC.

PPI analysis from OFC to the right posterior lobule VI (Table 2a, Fig. 2b) and from the left red nucleus to right OFC (Table 2d, Fig. 3c) denote that motivation induced by verbal encouragement could be maintained by OFC neurons. OFC activity is shown to be involved in motivational processes. It appears to subserve evaluation and learning of stimulusincentive associations, and thus plays a key role in the motivational control of goal-directed behavior. OFC is also involved in context-dependent stimulus coding, by responding differently to the same instruction cue as a function of its motivational significance [115].

In conjunction with OFC activity, significant ventral striatum activity (Table 1) suggests that this structure may also play an important role to support motivation during this motor task. This observation is in line with previous studies reporting that the basal ganglia can act as an interface between non-motor processes and motor processes [116]. The limbic part of the basal ganglia, which includes the ventral striatum and ventral pallidum, may convert motivation signals into motor signals [117]. Other studies have described striatal nuclei as critical nodes of topographically organized connections between cortical and subcortical areas. These areas are involved in processing motor, affective, and cognitive information [118].

The dense interconnection between the cerebellum and the ventral striatum $[119,120]$ may explain the significant PPI connectivity from lobule VI to ventral striatum (Table 2c, Fig. 3b). Both structures receive input from and send output to the cerebral cortex. Recent findings reveal the existence of an anatomical substrate for the bidirectional communication between the cerebellum and the basal ganglia. In particular, studies on rats [121] and monkeys have demonstrated that the cerebellum sends a strong disynaptic projection to the striatum through the thalamus. Similar evidence has been recently reported in the human brain [122]. Hoshi and colleagues [120] showed that the dentate nucleus has a disynaptic projection to an input stage of basal ganglia processing, the striatum. Besides its motivational involvement in this task, the striatum may also be involved in motor learning [23, 123] in conjunction with the cerebellum and the motor cortex [124, 125]. Penhune and Steele [13] propose that the role of the striatum is to learn predictive associations between the individual movements in the sequence. Furthermore, the role of the cerebellum is suggested to create an optimal internal model, while the function of $\mathrm{M} 1$ is the retention of the motor memory.

PPI connectivity from the posterior lobule VI to the ventral striatum (Table 2c, Fig. 3b) correlated to listed anatomical connections between these two structures, which can modulate motivation through multisynaptic loops with the cerebral cortex. The ventral striatum, mainly the nucleus accumbens, receives inputs from the "limbic" prefrontal cortex, [126, 127] 
and its outputs are directed back to the cerebral cortex via the striato-pallidothalamic and striato-nigro-thalamic pathways. Large numbers of cortical neurons project to the input stages of the basal ganglia and the cerebellum. Similarly, the output stages of the basal ganglia and the cerebellum project to subdivisions of the ventroanterior and ventrolateral thalamus. These regions of the thalamus then project back upon the cerebral cortex. Inputs from the cerebral cortices terminate in the pontine nuclei then project to the cerebellum. Subsequently, the feedback projections travel from the cerebellum via the deep cerebellar nuclei and terminate in the thalamus, which then sends projection back to both motor and non-motor cerebral cortices [128-130]. Thus, the cerebello-thalamocortical loop, formed by the interaction between the input and output stages of processing, were believed to provide a route by which information from cognitive, motivational, and motor domains influenced the generation and control of movement, all while participants were actively motivated.

Notwithstanding, this study has some limitations. The main one is the PPI interpretation way: we used a psychophysiological analysis demonstrating how the contribution of one region to another is altered by the experimental context. However, we did not analyze the other way of interpretation regarding how an area's response to an experimental context is modulated by input from another region. We definitely cannot exclude a possible different effect from this other way of interpretation. Further investigations are required for assessing effective (causal) connectivity using causal modeling (DCM) [131]. Other limitations are the lack of primary olivary nucleus activity and the failure to detect the neocerebello-rubro-olivoneocerebellar loop. Resting-state and tractography methods should partly overcome these limitations.

\section{Conclusion}

Several conclusions can be drawn: (1) verbal encouragement strongly and positively influences muscular force, (2) the right lobule VI (anterior and posterior parts) is dually recruited by the motoric and motivational aspect of the sensorimotor performance in conjunction with the contralateral red nucleus, (3) $\mathrm{RN}$ plays a main role in maintaining motivation through interactions with OFC and ventral striatum, and (4) these circuits correspond to a closed-connectivity-loop modulated by the red nucleus, a cerebro-cerebello-striatal loop and probably a cerebello-rubro-olivo-cerebellar loop.

\footnotetext{
Acknowledgments We would like to thank the participants that gave their time to take part in this study and everybody who has contributed to its realization
}

Compliance with Ethical Standards The study was approved by the local ethics committee.
Conflict of Interest The authors declare that they have no conflicts of interest.

\section{References}

1. McNair PJ, Depledge J, Brettkelly M, Stanley SN. Verbal encouragement: effects on maximum effort voluntary muscle action. Br J Sports Med. 1996;30(3):243-5.

2. Tod D, Iredale F, Gill N. "Psyching-up" and muscular force production. Sports Med. 2003;33(1):47-58.

3. Amagliani RM, Petrella JK, Jung AP. Type of encouragement influences peak muscle force in college-age women. Int J Exerc Sci. 2010;3(4):2.

4. Moffatt RJ, Chitwood LF, Biggerstaff KD. The influence of verbal encouragement during assessment of maximal oxygen uptake. J Sports Med Phys Fit. 1994;34(1):45-9.

5. Chitwood LF, Moffatt RJ, Burke K, Luchino P, Jordan JC. Encouragement during maximal exercise testing of type $\mathrm{A}$ and type B scorers. Percept Mot Skills. 1997;84(2):507-12.

6. Viru M, Hackney AC, Karelson K, Janson T, Kuus M, Viru A. Competition effects on physiological responses to exercise: performance, cardiorespiratory and hormonal factors. Acta Physiol Hung. 2010;97(1):22-30.

7. Andreacci JL, LeMura LM, Cohen SL, Urbansky EA, Chelland SA, Von Duvillard SP. The effects of frequency of encouragement on performance during maximal exercise testing. J Sports Sci. 2002;20(4):345-52.

8. Karaba-Jakovljevic D, Popadic-Gacesa J, Grujic N, Barak O, Drapsin M. Motivation and motoric tests in sports. Med Pregl. 2007;60(5-6):231-6.

9. Wulf G, Tollner T, Shea CH. Attentional focus effects as a function of task difficulty. Res Q Exerc Sport. 2007;78(3):257-64.

10. Stoodley CJ, Schmahmann JD. Functional topography in the human cerebellum: a meta-analysis of neuroimaging studies. NeuroImage. 2009;44(2):489-501.

11. Schoch B, Dimitrova A, Gizewski ER, Timmann D. Functional localization in the human cerebellum based on voxelwise statistical analysis: a study of 90 patients. NeuroImage. 2006;30(1):3651.

12. Shmuelof L, Krakauer JW. Are we ready for a natural history of motor learning? Neuron. 2011;72(3):469-76.

13. Penhune VB, Steele CJ. Parallel contributions of cerebellar, striatal and M1 mechanisms to motor sequence learning. Behav Brain Res. 2012;226(2):579-91.

14. Shadmehr R, Krakauer JW. A computational neuroanatomy for motor control. Exp Brain Res. 2008;185(3):359-81.

15. D'Angelo E, Mazzarello P, Prestori F, Mapelli J, Solinas S, Lombardo P, et al. The cerebellar network: from structure to function and dynamics. Brain Res Rev. 2011;66(1-2):5-15.

16. Manto MU, Jissendi P. Cerebellum: links between development, developmental disorders and motor learning. Front Neuroanat. 2012;6:1.

17. Hui SH, Wing YK, Poon W, Chan YL, Buckley TA. Alveolar hypoventilation syndrome in brainstem glioma with improvement after surgical resection. Chest. 2000;118(1):266-8.

18. Schmahmann JD, Pandya DN. The cerebrocerebellar system. Int Rev Neurobiol. 1997;41:31-60.

19. Schmahmann JD, Rosene DL, Pandya DN. Motor projections to the basis pontis in rhesus monkey. J Comp Neurol. 2004;478(3): 248-68. 
20. Tan RH, Devenney E, Kiernan MC, Halliday GM, Hodges JR, Hornberger M. Terra incognita-cerebellar contributions to neuropsychiatric and cognitive dysfunction in behavioral variant frontotemporal dementia. Front Aging Neurosci. 2015;7:121.

21. Pessiglione M, Schmidt L, Draganski B, Kalisch R, Lau H, Dolan RJ, et al. How the brain translates money into force: a neuroimaging study of subliminal motivation. Science. 2007;316(5826): 904-6.

22. Schmidt L, Lebreton M, Clery-Melin ML, Daunizeau J, Pessiglione M. Neural mechanisms underlying motivation of mental versus physical effort. PLoS Biol. 2012;10(2), e1001266.

23. Doyon J, Owen AM, Petrides M, Sziklas V, Evans AC. Functional anatomy of visuomotor skill learning in human subjects examined with positron emission tomography. Eur J Neurosci. 1996;8(4): 637-48.

24. Doyon J, Orban P, Barakat M, Debas K, Lungu O, Albouy G, et al. Functional brain plasticity associated with motor learning. Med Sci: M/S. 2011;27(4):413-20.

25. Albouy G, King BR, Maquet P, Doyon J. Hippocampus and striatum: dynamics and interaction during acquisition and sleeprelated motor sequence memory consolidation. Hippocampus. 2013;23(11):985-1004.

26. Kuypers HG. Some aspects of the organization of the output of the motor cortex. Ciba Found Symp. 1987;132:63-82.

27. Kringelbach ML. The human orbitofrontal cortex: linking reward to hedonic experience. Nat Rev Neurosci. 2005;6(9):691-702.

28. Wallis JD. Orbitofrontal cortex and its contribution to decisionmaking. Annu Rev Neurosci. 2007;30:31-56.

29. Rolls ET. Functions of the orbitofrontal and pregenual cingulate cortex in taste, olfaction, appetite and emotion. Acta Physiol Hung. 2008;95(2):131-64.

30. Mainen ZF, Kepecs A. Neural representation of behavioral outcomes in the orbitofrontal cortex. Curr Opin Neurobiol. 2009;19(1):84-91.

31. Haber SN, Knutson B. The reward circuit: linking primate anatomy and human imaging. Neuropsychopharmacol: Off Publ Am Coll Neuropsychopharmacol. 2010;35(1):4-26.

32. Grabenhorst F, Rolls ET. Value, pleasure and choice in the ventral prefrontal cortex. Trends Cogn Sci. 2011;15(2):56-67.

33. Ruff CC, Fehr E. The neurobiology of rewards and values in social decision making. Nat Rev Neurosci. 2014;15(8):549-62.

34. Sugrue LP, Corrado GS, Newsome WT. Choosing the greater of two goods: neural currencies for valuation and decision making. Nat Rev Neurosci. 2005;6(5):363-75.

35. Murray EA, Izquierdo A. Orbitofrontal cortex and amygdala contributions to affect and action in primates. Ann N Y Acad Sci. 2007;1121:273-96.

36. Kim S, Lee D. Prefrontal cortex and impulsive decision making. Biol Psychiatry. 2011;69(12):1140-6.

37. Bartra O, McGuire JT, Kable JW. The valuation system: a coordinate-based meta-analysis of BOLD fMRI experiments examining neural correlates of subjective value. NeuroImage. 2013;76:412-27.

38. Miller EK, Cohen JD. An integrative theory of prefrontal cortex function. Annu Rev Neurosci. 2001;24:167-202.

39. Hoshi E. Functional specialization within the dorsolateral prefrontal cortex: a review of anatomical and physiological studies of non-human primates. Neurosci Res. 2006;54(2):73-84.

40. Petrides M. Functional organization of the human frontal cortex for mnemonic processing. Evidence from neuroimaging studies. Ann N Y Acad Sci. 1995;769:85-96.

41. Postle BR, Berger JS, Taich AM, D'Esposito M. Activity in human frontal cortex associated with spatial working memory and saccadic behavior. J Cogn Neurosci. 2000;12 Suppl 2:2-14.

42. Wallis JD, Anderson KC, Miller EK. Single neurons in prefrontal cortex encode abstract rules. Nature. 2001;411(6840):953-6.
43. Barraclough DJ, Conroy ML, Lee D. Prefrontal cortex and decision making in a mixed-strategy game. Nat Neurosci. 2004;7(4):404-10.

44. Buckley MJ, Mansouri FA, Hoda H, Mahboubi M, Browning PG, Kwok SC, et al. Dissociable components of rule-guided behavior depend on distinct medial and prefrontal regions. Science. 2009;325(5936):52-8.

45. Wernicke C. Der aphasiche Symptomenkomplex: eine psychologische Studie auf anatomischer Basis. Breslau: Cohen and Weigert; 1874.

46. Tzourio-Mazoyer N, Landeau B, Papathanassiou D, Crivello F, Etard O, Delcroix N, et al. Automated anatomical labeling of activations in SPM using a macroscopic anatomical parcellation of the MNI MRI single-subject brain. NeuroImage. 2002;15(1): 273-89.

47. Friston KJ, Buechel C, Fink GR, Morris J, Rolls E, Dolan RJ. Psychophysiological and modulatory interactions in neuroimaging. NeuroImage. 1997;6(3):218-29.

48. Passamonti L, Rowe JB, Ewbank M, Hampshire A, Keane J, Calder AJ. Connectivity from the ventral anterior cingulate to the amygdala is modulated by appetitive motivation in response to facial signals of aggression. NeuroImage. 2008;43(3):562-70.

49. Eickhoff SB, Stephan KE, Mohlberg H, Grefkes C, Fink GR, Amunts K, et al. A new SPM toolbox for combining probabilistic cytoarchitectonic maps and functional imaging data. NeuroImage. 2005;25(4):1325-35.

50. Eickhoff SB, Heim S, Zilles K, Amunts K. Testing anatomically specified hypotheses in functional imaging using cytoarchitectonic maps. NeuroImage. 2006;32(2):570-82.

51. Diedrichsen J, Balsters JH, Flavell J, Cussans E, Ramnani N. A probabilistic MR atlas of the human cerebellum. NeuroImage. 2009;46(1):39-46.

52. Schmahmann JD, Doyon J, Petrides M, Evans AC, Toga AW. MRI atlas of the human cerebellum: Academic Press; 2000.

53. Bickers MJ. Does verbal encouragement work? The effect of verbal encouragement on a muscular endurance task. Clin Rehabil. 1993;7(3):196-200.

54. Binboga E, Tok S, Catikkas F, Guven S, Dane S. The effects of verbal encouragement and conscientiousness on maximal voluntary contraction of the triceps surae muscle in elite athletes. $\mathrm{J}$ Sports Sci. 2013;31(9):982-8.

55. Belanger AY, McComas AJ. Extent of motor unit activation during effort. J Appl Physiol Respir Environ Exerc Physiol. 1981;51(5):1131-5.

56. Kelly RM, Strick PL. Cerebellar loops with motor cortex and prefrontal cortex of a nonhuman primate. J Neurosci: Off J Soc Neurosci. 2003;23(23):8432-44.

57. Smith AM, Bourbonnais D. Neuronal activity in cerebellar cortex related to control of prehensile force. J Neurophysiol. 1981;45(2): 286-303.

58. Sehm B, Perez MA, Xu B, Hidler J, Cohen LG. Functional neuroanatomy of mirroring during a unimanual force generation task. Cereb Cortex. 2010;20(1):34-45.

59. Dettmers C, Fink GR, Lemon RN, Stephan KM, Passingham RE, Silbersweig D, et al. Relation between cerebral activity and force in the motor areas of the human brain. J Neurophysiol. 1995;74(2):802-15.

60. Keisker B, Hepp-Reymond MC, Blickenstorfer A, Meyer M, Kollias SS. Differential force scaling of fine-graded power grip force in the sensorimotor network. Hum Brain Mapp. 2009;30(8): 2453-65.

61. Pope P, Wing AM, Praamstra P, Miall RC. Force related activations in rhythmic sequence production. NeuroImage. 2005;27(4): 909-18.

62. Spraker MB, Corcos DM, Kurani AS, Prodoehl J, Swinnen SP, Vaillancourt DE. Specific cerebellar regions are related to force 
amplitude and rate of force development. NeuroImage. 2012;59(2):1647-56.

63. Wolpert DM, Miall RC, Kawato M. Internal models in the cerebellum. Trends Cogn Sci. 1998;2(9):338-47.

64. Ohyama T, Nores WL, Murphy M, Mauk MD. What the cerebellum computes. Trends Neurosci. 2003;26(4):222-7.

65. Rao SM, Mayer AR, Harrington DL. The evolution of brain activation during temporal processing. Nat Neurosci. 2001;4(3):31723.

66. Ivry RB, Spencer RM. The neural representation of time. Curr Opin Neurobiol. 2004;14(2):225-32.

67. Meck WH. Neuropsychology of timing and time perception. Brain Cogn. 2005;58(1):1-8.

68. Braitenberg V. Is the cerebellar cortex a biological clock in the millisecond range? Prog Brain Res. 1967;25:334-46.

69. Ivry RB, Keele SW, Diener HC. Dissociation of the lateral and medial cerebellum in movement timing and movement execution. Exp Brain Res. 1988;73(1):167-80.

70. Jahanshahi M, Jones CR, Dirnberger G, Frith CD. The substantia nigra pars compacta and temporal processing. J Neurosci: Off J Soc Neurosci. 2006;26(47):12266-73.

71. Schmahmann JD, Sherman JC. The cerebellar cognitive affective syndrome. Brain: J Neurol. 1998;121(4):561-79.

72. Manto M-U, Pandolfo M. The cerebellum and its disorders. Cambridge: Cambridge University Press; 2002.

73. Bares M, Lungu O, Liu T, Waechter T, Gomez CM, Ashe J. Impaired predictive motor timing in patients with cerebellar disorders. Exp Brain Res. 2007;180(2):355-65.

74. Chandran V, Pal PK. Essential tremor: beyond the motor features. Parkinsonism Relat Disord. 2012;18(5):407-13.

75. Ullen F, Forssberg H, Ehrsson HH. Neural networks for the coordination of the hands in time. J Neurophysiol. 2003;89(2):112635 .

76. Timmann D, Watts S, Hore J. Failure of cerebellar patients to time finger opening precisely causes ball high-low inaccuracy in overarm throws. J Neurophysiol. 1999;82(1):103-14.

77. Lewis $\mathrm{P}$, Miall R. Brain activation patterns during measurement of sub-and supra-second intervals. Neuropsychologia. 2003;41(12): 1583-92.

78. Xu D, Liu T, Ashe J, Bushara KO. Role of the olivo-cerebellar system in timing. J Neurosci. 2006;26(22):5990-5.

79. Perrett SP, Ruiz BP, Mauk MD. Cerebellar cortex lesions disrupt learning-dependent timing of conditioned eyelid responses. J Neurosci. 1993;13(4):1708-18.

80. Gerwig M, Hajjar K, Dimitrova A, Maschke M, Kolb FP, Frings $\mathrm{M}$, et al. Timing of conditioned eyeblink responses is impaired in cerebellar patients. J Neurosci. 2005;25(15):3919-31.

81. Molinari M, Leggio MG, Thaut MH. The cerebellum and neural networks for rhythmic sensorimotor synchronization in the human brain. Cerebellum. 2007;6(1):18-23.

82. O'Reilly JX, Beckmann CF, Tomassini V, Ramnani N, JohansenBerg H. Distinct and overlapping functional zones in the cerebellum defined by resting state functional connectivity. Cereb Cortex. 2010;20(4):953-65.

83. Stoodley CJ, Stein JF. The cerebellum and dyslexia. Cortex. 2011;47(1):101-16. a journal devoted to the study of the nervous system and behavior.

84. Chen X, Scangos KW, Stuphorn V. Supplementary motor area exerts proactive and reactive control of arm movements. J Neurosci: Off J Soc Neurosci. 2010;30(44):14657-75.

85. Dhamala M, Pagnoni G, Wiesenfeld K, Zink CF, Martin M, Berns GS. Neural correlates of the complexity of rhythmic finger tapping. NeuroImage. 2003;20(2):918-26.

86. Lewis PA, Wing AM, Pope PA, Praamstra P, Miall RC. Brain activity correlates differentially with increasing temporal complexity of rhythms during initialisation, synchronisation, and continuation phases of paced finger tapping. Neuropsychologia. 2004;42(10):1301-12.

87. van der Gaag C, Minderaa RB, Keysers C. Facial expressions: what the mirror neuron system can and cannot tell us. Soc Neurosci. 2007;2(3-4):179-222.

88. Molenberghs P, Cunnington R, Mattingley JB. Brain regions with mirror properties: a meta-analysis of 125 human fMRI studies. Neurosci Biobehav Rev. 2012;36(1):341-9.

89. Nioche C, Cabanis EA, Habas C. Functional connectivity of the human red nucleus in the brain resting state at 3T. AJNR Am J Neuroradiol. 2009;30(2):396-403.

90. Schmahmann JD, Doyon J, McDonald D, Holmes C, Lavoie K Hurwitz AS, et al. Three-dimensional MRI atlas of the human cerebellum in proportional stereotaxic space. NeuroImage. 1999;10(3 Pt 1):233-60.

91. Schmahmann JD, Caplan D. Cognition, emotion and the cerebellum. Brain: J Neurol. 2006;129(Pt 2):290-2.

92. Glickstein M, May 3rd JG, Mercier BE. Corticopontine projection in the macaque: the distribution of labelled cortical cells after large injections of horseradish peroxidase in the pontine nuclei. J Comp Neurol. 1985;235(3):343-59.

93. Palesi F, Tournier JD, Calamante F, Muhlert N, Castellazzi G, Chard D, et al. Contralateral cerebello-thalamo-cortical pathways with prominent involvement of associative areas in humans in vivo. Brain Struct Funct. 2015;220(6):3369-84.

94. Apps R, Hawkes R. Cerebellar cortical organization: a one-map hypothesis. Nat Rev Neurosci. 2009;10(9):670-81.

95. Brochu G, Maler L, Hawkes R. Zebrin II: a polypeptide antigen expressed selectively by Purkinje cells reveals compartments in rat and fish cerebellum. J Comp Neurol. 1990;291(4):538-52.

96. Sugihara I. Compartmentalization of the deep cerebellar nuclei based on afferent projections and aldolase $\mathrm{C}$ expression. Cerebellum. 2011;10(3):449-63.

97. Voogd J. Cerebellar zones: a personal history. Cerebellum. 2011;10(3):334-50.

98. Voogd J, Ruigrok TJ. The organization of the corticonuclear and olivocerebellar climbing fiber projections to the rat cerebellar vermis: the congruence of projection zones and the zebrin pattern. $\mathrm{J}$ Neurocytol. 2004;33(1):5-21.

99. Oscarsson O. Functional units of the cerebellum-sagittal zones and microzones. Trends Neurosci. 1979;2:143-5.

100. Voogd J, Glickstein M. The anatomy of the cerebellum. Trends Neurosci. 1998;21(9):370-5.

101. Sugihara I, Shinoda Y. Molecular, topographic, and functional organization of the cerebellar cortex: a study with combined aldolase C and olivocerebellar labeling. J Neurosci. 2004;24(40): 8771-85.

102. De Zeeuw CI, Hoebeek FE, Bosman LW, Schonewille M, Witter L, Koekkoek SK. Spatiotemporal firing patterns in the cerebellum. Nat Rev Neurosci. 2011;12(6):327-44.

103. Voogd J. Comparative aspects of the structure and fibre connexions of the mammalian cerebellum. Prog Brain Res. 1966;25:94 134.

104. Ruigrok TJ. Ins and outs of cerebellar modules. Cerebellum. 2011;10(3):464-74

105. Pijpers A, Apps R, Pardoe J, Voogd J, Ruigrok TJ. Precise spatial relationships between mossy fibers and climbing fibers in rat cerebellar cortical zones. J Neurosci. 2006;26(46):12067-80.

106. Voogd J, Pardoe J, Ruigrok TJ, Apps R. The distribution of climbing and mossy fiber collateral branches from the copula pyramidis and the paramedian lobule: congruence of climbing fiber cortical zones and the pattern of zebrin banding within the rat cerebellum. J Neurosci. 2003;23(11):4645-56.

107. Ito M. Control of mental activities by internal models in the cerebellum. Nat Rev Neurosci. 2008;9(4):304-13. 
108. Buckner RL, Krienen FM, Castellanos A, Diaz JC, Yeo BT. The organization of the human cerebellum estimated by intrinsic functional connectivity. J Neurophysiol. 2011;106(5):2322-45.

109. Buckner RL. The cerebellum and cognitive function: 25 years of insight from anatomy and neuroimaging. Neuron. 2013;80(3): 807-15.

110. Habas C, Cabanis EA. Cortical projections to the human red nucleus: a diffusion tensor tractography study with a $1.5-\mathrm{T}$ MRI machine. Neuroradiology. 2006;48(10):755-62.

111. Habas C, Kamdar N, Nguyen D, Prater K, Beckmann CF, Menon $\mathrm{V}$, et al. Distinct cerebellar contributions to intrinsic connectivity networks. J Neurosci: Off J Soc Neurosci. 2009;29(26):8586-94.

112. Ito M. The modifiable neuronal network of the cerebellum. Jpn J Physiol. 1984;34(5):781-92.

113. Eccles JC. Circuits in the cerebellar control of movement. Proc Natl Acad Sci U S A. 1967;58(1):336-43.

114. Habas $\mathrm{C}$, Guillevin R, Abanou A. In vivo structural and functional imaging of the human rubral and inferior olivary nuclei: a minireview. Cerebellum. 2010;9(2):167-73.

115. Watanabe M, Sakagami M. Integration of cognitive and motivational context information in the primate prefrontal cortex. Cereb Cortex. 2007;17 Suppl 1:1101-9.

116. Haber SN. The primate basal ganglia: parallel and integrative networks. J Chem Neuroanat. 2003;26(4):317-30.

117. Mogenson GJ, Jones DL, Yim CY. From motivation to action: functional interface between the limbic system and the motor system. Prog Neurobiol. 1980;14(2-3):69-97.

118. Schmahmann JD, Pandya DN. Disconnection syndromes of basal ganglia, thalamus, and cerebrocerebellar systems. Cortex. 2008;44(8):1037-66. a journal devoted to the study of the nervous system and behavior.

119. Bostan AC, Dum RP, Strick PL. The basal ganglia communicate with the cerebellum. Proc Natl Acad Sci U S A. 2010;107(18): 8452-6.

120. Hoshi E, Tremblay L, Feger J, Carras PL, Strick PL. The cerebellum communicates with the basal ganglia. Nat Neurosci. 2005;8(11):1491-3.
121. Ichinohe N, Mori F, Shoumura K. A di-synaptic projection from the lateral cerebellar nucleus to the laterodorsal part of the striatum via the central lateral nucleus of the thalamus in the rat. Brain Res. 2000;880(1-2):191-7.

122. Pelzer EA, Hintzen A, Goldau M, von Cramon DY, Timmermann L, Tittgemeyer M. Cerebellar networks with basal ganglia: feasibility for tracking cerebello-pallidal and subthalamo-cerebellar projections in the human brain. Eur J Neurosci. 2013;38(8): 3106-14.

123. Grafton ST, Hazeltine E, Ivry R. Functional mapping of sequence learning in normal humans. J Cogn Neurosci. 1995;7(4):497-510.

124. Rauch SL, Baer L, Cosgrove GR, Jenike MA. Neurosurgical treatment of Tourette's syndrome: a critical review. Compr Psychiatry. 1995;36(2):141-56.

125. Krinke GJ, Classen W, Rauch M, Weber E. Optimal conduct of the neuropathology evaluation of organophosphorus induced delayed neuropathy in hens. Exp Toxicol Pathol: Off J Gesellschaft fur Toxikologische Pathologie. 1997;49(6):451-8.

126. Daw ND, Doya K. The computational neurobiology of learning and reward. Curr Opin Neurobiol. 2006;16(2):199-204.

127. O'Doherty JP, Hampton A, Kim H. Model-based fMRI and its application to reward learning and decision making. Ann N Y Acad Sci. 2007;1104:35-53.

128. Hui KK, Liu J, Marina O, Napadow V, Haselgrove C, Kwong KK, et al. The integrated response of the human cerebro-cerebellar and limbic systems to acupuncture stimulation at ST 36 as evidenced by fMRI. NeuroImage. 2005;27(3):479-96.

129. Stoodley CJ, Valera EM, Schmahmann JD. An fMRI study of intra-individual functional topography in the human cerebellum. Behav Neurol. 2010;23(1-2):65-79.

130. Marien P, Beaton A. The enigmatic linguistic cerebellum: clinical relevance and unanswered questions on nonmotor speech and language deficits in cerebellar disorders. Cerebellum Ataxias. 2014;1: 12.

131. Friston KJ, Harrison L, Penny W. Dynamic causal modelling. NeuroImage. 2003;19(4):1273-302. 